\title{
Correction: Quantitative ultrasound assessment of breast tumor response to chemotherapy using a multi-parameter approach
}

\section{Hadi Tadayyon, Lakshmanan Sannachi, Mehrdad Gangeh, Ali Sadeghi-Naini, William Tran, Maureen E. Trudeau, Kathleen Pritchard, Sonal Ghandi, Sunil Verma, Gregory J. Czarnota}

Copyright: Tadayyon et al. This is an open-access article distributed under the terms of the Creative Commons Attribution License (CC-BY), which permits unrestricted use, distribution, and reproduction in any medium, provided the original author and source are credited.

Present: The funding acknowledgements were omitted from the original paper.

Correct: The proper funding acknowledgements are given below.

Original article: Oncotarget. 2016; 7:45094-45111. doi: 10.18632/oncotarget.8862

\section{ACKNOWLEDGEMENTS}

This study was funded by the Terry Fox Foundation. Partly during this study, H.T. held a Natural Sciences and Engineering Research Council of Canada Postgraduate Scholarship, M.G. held a Natural Sciences and Engineering Research Council of Canada Post-doctoral Fellowship, A.S.N. held a Banting Postdoctoral Fellowship and Canadian Breast Cancer Foundation Postdoctoral Fellowship, and G.J.C. held a Cancer Care Ontario Research Chair in Experimental Therapeutics and Imaging and now holds University of Toronto James and Mary Davie Chair in Breast Cancer Imaging and Ablation. 